\title{
Opioid-mediated Sertoli cells apoptosis is involved in testicular homeostasis and/or reproductive dysfunction
}

\author{
Soltanineghad $\mathrm{M}^{1,3}$, Roshan-Milani $\mathrm{S}^{1,2}$, Saboory $\mathrm{E}^{1,2}$, Kheradmand $\mathrm{F}^{3,4}$, Pourheydar $\mathrm{M}^{5}$, \\ Pourheydar B ${ }^{2,6}$, Motazakker $\mathrm{M}^{3}$, Chodari L ${ }^{1,2}$
}

Department of Physiology, Faculty of Medicine, Urmia University of Medical Sciences, Urmia, Iran.

shivamilani@umsu.ac.ir

\begin{abstract}
OBJECTIVES: The opioid system may exert positive direct and/or indirect effects on spermatogenesis at multiple levels including the levels of the central nervous system and at the testes/sperm levels. However, long term opioid use could be associated with several reproductive complications that place the users at risk of hypogonadism and even infertility. There is little available information regarding the contribution of opioids and their apoptotic effects on testis Sertoli cells. Here, the effects of DAMGO (mu opioid receptor's agonist), DPDPE (delta opioid receptor's agonist) and DYN 1-9 (kappa opioid receptor's agonist) on Sertoli cell viability and apoptosis were investigated.

METHODS: Cultured Sertoli cells were exposed to each agonist $(0.1-100 \mu \mathrm{M}$, for 24 or 48 hours) and their apoptotic effects were investigated.

RESULTS: Cell viability was decreased and apoptosis was increased in the cells exposed to DAMGO in a concentration-dependent manner, while in the cells exposed to DPDPE, no significant changes were observed. In cells exposed to DYN 1-9, the viability did not significantly change, however apoptosis increased significantly, following the exposure to the high concentration of DYN 1-9.

CONCLUSION: These data suggest that mu and Kappa, but not delta receptors mediated apoptosis in Sertoli cells may be involved, at least in part, in testicular homeostasis and/or reproductive dysfunction (Tab. 1, Fig. 3, Ref. 52). Text in PDF www.elis.sk

KEY WORDS: opioids, Sertoli cell, apoptosis, cell viability, infertility, testicular homeostasis.
\end{abstract}

\section{Introduction}

The opioid system is the key mediator in cell biological communication, containing receptors for endogenous and exogenous opioid peptides. The opioid peptides exert their physiological actions at both central and peripheral levels through 3 main classes of opioid receptors: the mu-opioid receptor (MOR), the delta-opioid receptor (DOR) and the kappa-opioid receptor (KOR), which are distributed in various organs and tissues (1-2). Evidence of the widespread presence of opioid peptides and receptors in different tissues of the male reproductive system indicates that opioids may

${ }^{1}$ Department of Physiology, Faculty of Medicine, Urmia University of Medical Sciences, Urmia, Iran, ${ }^{2}$ Neurophysiology Research Center, Urmia University of Medical Sciences, Urmia, Iran, ${ }^{3}$ Cellular and Molecular Research Center, Urmia University of Medical Sciences, Urmia, Iran, ${ }^{4}$ Department of Clinical Biochemistry, Faculty of Medicine, Urmia University of Medical Sciences, Urmia, Iran, ${ }^{5}$ Department of Clinical \& Medical Pathology, Faculty of Medicine, Urmia University of Medical Sciences, Urmia, Iran, and ${ }^{6}$ Department of Anatomical Sciences, Faculty of Medicine, Urmia University of Medical Sciences, Urmia, Iran

Address for correspondence: S. Roshan-Milani, MD, PhD, Department of Physiology \&Neurophysiology Research Center, Urmia University of Medical Sciences, Urmia, Iran 5756115111.

Phone: +984432770698, Fax: +984432780801

Acknowledgement: This study was supported by the Research Council of Urmia University of Medical Sciences, Urmia, Iran. participate in the regulation of reproductive function. The opioid system can participate in the regulation of male reproductive system at multiple levels including: the levels of the central nervous system (particularly through the hypothalamic-pituitary-gonadal axis), the testes level and sperm level (3). The presence of mu, delta and kappa opioid receptors on human and rodent sperm and Sertoli cells has been previously reported (4-5). In spite of the role of opioid peptides in regulating testicular function, long term opioid use, however is associated with several reproductive complications that place the users at risk for hypogonadism and even infertility (6-9). The direct and indirect effects of opioid peptides on the testes, including a decreased production of sperm, testicular interstitial fluid, testosterone and other sex hormones, demonstrated that opioid system might contribute to male reproductive dysfunction (6-11). Opioid system can lead to completely different and paradoxical effects on sperm count and motility (12-16), sperm modification (17-18) and other reproductive factors depending on opioid receptor subtypes, affinity, expression/localization patterns and opiate concentration level (3).

Opioid peptides have also been reported to influence cell proliferation and apoptosis. Morphine-mediated apoptosis has been identified in endothelial, immune, neuron, and cancer cells through its mu receptors (19-23). Morphine can also augment testis cell apoptosis (24). However, anti-apoptotic effects of opioids have also been reported mainly through activation of delta opioid 
receptors (25-27). Since preserving the delicate balance between cell survival and death is of the extreme importance for the proper development of testicular cells and subsequent fertility, a better understanding of the implication of the opioid system in these processes may contribute to clarify the role of opioid peptides on testicular homeostasis and even etiology of many cases of infertility in patients taking opioid medications and in opiate abusers. As most of the previous works have been focused on the effect of opioids on testicular germ cells and sperm, there is little available information regarding their effects on the Sertoli cells. Given that the precise mechanism underling opioid mediated reproductive dysfunction has yet to be fully elucidated and no studies have examined the modulation of apoptosis and cell-cycle regulation by opioid peptides in testicular Sertoli cells, this study has been performed. In the present study, the effects of different concentrations of mu, delta and kappa opioid receptors' selective agonists on Sertoli cell viability and apoptosis were investigated to determine whether opioids may contribute to testicular homeostasis and/or reproductive dysfunction.

\section{Material and methods}

\section{Cell line and culture conditions}

The Mus Musculus Sertoli cell line, TM4 (purchased from Pasteur Institute, Tehran, Iran) was used in all experiments. The TM4 cells were cultured in Dulbecco's Modified Eagle's Medium (DMEM)F12/hepes media (Atocel, Austria) supplemented with fetal bovine serum, Horse serum, penicillin and streptomycin, in tissue flasks maintained at $37^{\circ} \mathrm{C}$ in a cell incubator, as previously reported (28).

\section{Cell viability (MTT assay)}

Cell viability was determined using the MTT (3-(4,5-Dimethylthiazol-2-yl)-2,5-diphenyltetrazolium bromide) reagent powder (Sigma M5655-1G,Germany) according to the manufacturer's protocol (28). In order to determine the effect of different opiates, in each of duplicate cultures, TM4 cells for two different exposure periods were seeded to two separate 96-well culture plates at a density of $5 \times 10^{3}$ cells/well. The cells of both plates (for each duration period) were seeded at the same time, with the same density. After a stabilization period of $24 \mathrm{~h}$, the medium was aspirated from each well and replaced with an opiate containing medium for treatment wells and a free fresh medium for control wells. Cells were treated with different opioid receptor agonists (Bachem AG, Bubendorf, Switzerland), including MOR selective agonist (D-Ala ${ }^{2}, \mathrm{~N}-\mathrm{Me}-\mathrm{Phe}^{4}$, glycinol ${ }^{5}$ )-Enkephalin acetate salt (DAMGO), DOR selective agonist (D-Pen ${ }^{2}, \mathrm{D}-\mathrm{Pen}^{5}$ )Enkephalin (DPDPE) and KOR selective agonist Dynorphin A 1-9 (DYN 1-9) at concentrations of $0,0.1,1,10$ and $100 \mu \mathrm{M}$ (4 wells each agonist/concentration, total number of 64 treatment wells; and the control group of 10 wells). After $24 \mathrm{~h}$, the cells of $24 \mathrm{~h}$ exposure period were used for MTT assay, according to the manufacturer's instructions, but the cells of second plate $(48 \mathrm{~h}$ exposure subgroup) were treated for an additional $24 \mathrm{~h}$ exposure period. Following MTT assay, the absorbance and optical density (O.D.) were measured with a micro plate reader at $570 \mathrm{~nm}$. The percentage of viable cells was calculated as followed: Percentage specific viability $=A / B \times 100$, where $A=O_{570}$ of the treated sample, $\mathrm{B}=\mathrm{OD}_{570}$ of the controls.

\section{Cell apoptosis (TUNEL assay)}

In another set of experiments, TUNEL(Terminal Deoxynucleotidyl Transferase-Mediated dUTP end Labeling) assay was performed using in situ cell death detection Kit PoD (Roche, Germany) for in situ detection of apoptotic cells. Following the primary MTT experiments and analysis, two intermediate and subtoxic concentrations of 1 and $100 \mu \mathrm{M}$ for each agonist were considered for the next phase of the study. TM4 cells for two different exposure periods were seeded to two separate 96-well culture plates at a density of $5 \times 10^{3}$ cells/well ( 3 wells each agonist/ concentration, total number of 18 treatment wells; and control group of 6 wells). After a stabilization period of $24 \mathrm{~h}$, the medium was aspirated from each well (in both 24 and $48 \mathrm{~h}$ exposure plates) and replaced with an opiate containing medium for treatment wells and a free fresh medium for control wells. At the end of exposure duration periods, TUNEL assay was performed according to the manufacturer's instructions (29). After mounting, the slides were examined by a light microscope.

\section{Cell counting and apoptotic index determination}

Apoptotic index was determined according to previously reported protocols (29). Accordingly, apoptotic Sertoli cells were counted at $40 \mathrm{x}$ magnification after which the mean number of apoptotic cells in the 10-15 microscopic fields was calculated. Apoptosis was expressed as the number of apoptotic cells per number of total nuclei counted in the same microscopic field. The apoptotic index was determined for each group as followed: Apoptotic index $=$ number of apoptotic cells /total number of cells $\times 100$.

\section{Statistical analysis}

The data were presented as the mean \pm standard error derived from two determinations in duplicate cultures. All data were normally distributed according to the Kolmogorov-Smirnov test. Oneway ANOVA followed by Tukey's HSD post-hoc test was performed to compare the differences in cell viability for each agonist, using GraphPad Instat (version 3.05) statistical analysis software. Data related to cell apoptosis was analyzed for three factors of "groups" (opioid agonists and control), "concentration" and "exposure duration", using three-way ANOVA. For the comparison of the apoptotic index within the experimental groups at each time point (24 or 48 h), baseline ANOVA was also performed, followed by Tukey's posthoc test, when required. Two-group comparison of apoptotic index between 24 and 48 hours exposure periods were performed using unpaired t-test. The level of significant difference was set at $p<0.05$.

\section{Results}

Effects of MOR, DOR and KOR agonists on Sertoli cell viability (MTT assay)

First, data of each exposure time was separately analyzed. There was no significant difference between 24 and 48 hours 

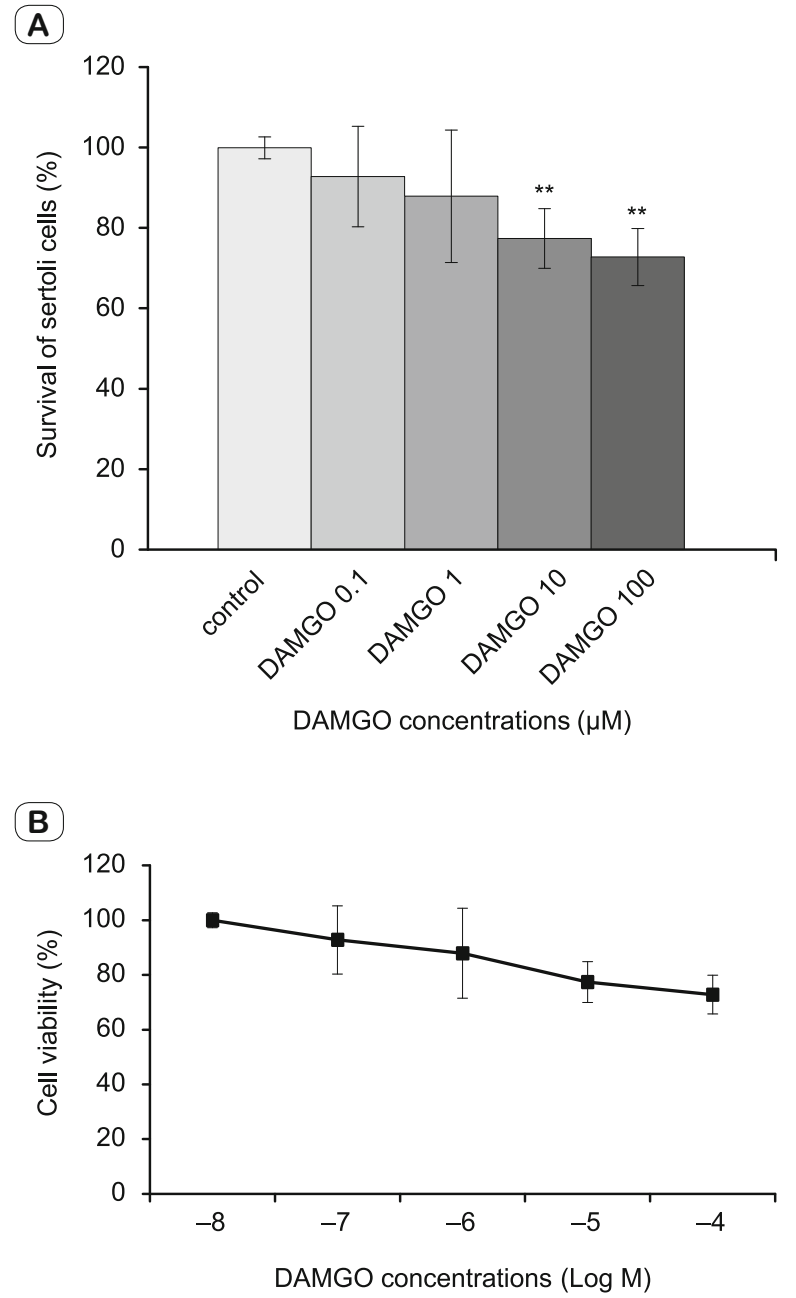

Fig. 1. The effect of MOR selective agonist (DAMGO) on TM4 cell viability. A: Comparison of the effects of different concentrations of DAMGO on TM4 cell viability following 24 hours exposure period. ** represents $p<0.01$ compared to the control group (one-way ANOVA). B: Line plot showing the normalised cell viability of TM4 cells in the presence of DAMGO. As the concentration of DAMGO increased, cellular viability decreased and eventually reached to approximately $72 \%$ of control level at concentration of $100 \mu \mathrm{M}$. All results are presented as the mean \pm SEM derived from two determinations in duplicate cultures.

opioids exposure in cell viability in the most MTT experiments. Therefore, 48-hour exposure data was not presented in this report. According to our results, in cells exposed to DAMGO, the viability decreased (in comparison to the control group) as concentration of DAMGO increased, however significant changes were only found in cells exposed to higher concentrations of DAMGO (10 and 100 $\mu \mathrm{M})$ (Fig. 1A). Accordingly, cell viability significantly decreased from $99.93 \pm 2.73 \%$ in the control group to $77.4 \pm 7.42 \%$ and $72.8 \pm 7.1 \%$, in cells exposed to 10 and $100 \mu \mathrm{M}$ DAMGO, respectively $(\mathrm{p}<0.01)$. DAMGO decreased the viability and inhibited proliferation of TM4 cells in a concentration-dependent manner
24 HOURS EXPOSURE PERIOD

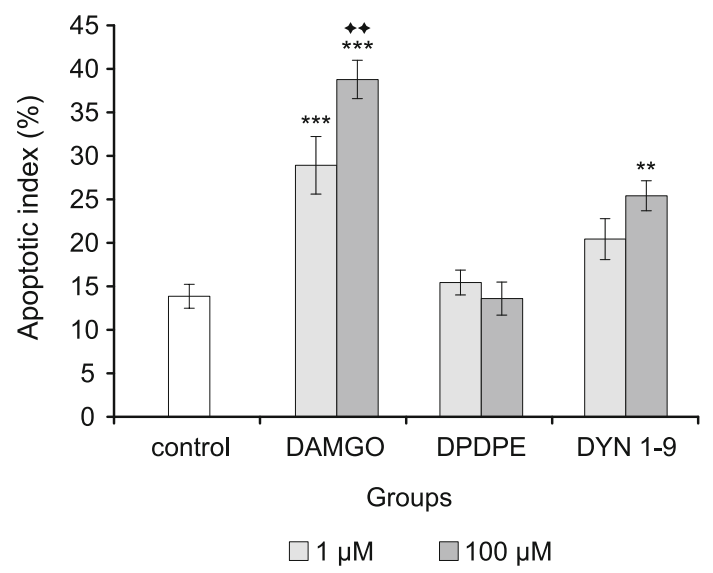

Fig. 2. The effect of opioid receptors selective agonists on TM4 cell apoptosis following $24 \mathrm{~h}$ exposure period. Comparison of the effects of two concentrations of MOR selective agonist (DAMGO), DOR selective agonist (DPDPE), and KOR selective agonist (DYN1-9) on the apoptotic index of TM4 cells following 24 hours exposure period. *** represents $p<0.001$ and $* *$ represents $p<0.01$ compared to the control group, ${ }^{++}$represents $p=0.03$ compared to DAMGO $1 \mu M$ (baseline, one-way ANOVA). In order to show the most relevant results (difference between opioid groups and control), not all significant changes are shown. All results are presented as the mean \pm SEM.

with $\mathrm{IC}_{50}$ values of $4 \times 10^{-3} \mathrm{M}$ (CompuSyn) (Fig. 1B). However, no significant changes were observed in cells exposed to either DPDPE or DYN 1-9 (data not presented).

\section{Effects of MOR, DOR and KOR agonists on Sertoli cell apoptosis (TUNEL assay)}

Following our primary observation that DAMGO decreased the viability and inhibited proliferation of TM4 cells with $\mathrm{IC}_{50}$ values of $4 \times 10^{-3} \mathrm{M}$, on the basis of these results and in order to confirm or modify the initial findings, in another set of experiments we planned the Tunnel Assay using intermediated and subtoxic concentrations of 1 and $100 \mu \mathrm{M}$ for each agonist, in two exposure times of 24 and $48 \mathrm{~h}$. Accordingly, cultured TM4 cells were exposed to 1 or $100 \mu \mathrm{M}$ of DAMGO, DPDPE and DYN 1-9 for 24 or 48 hours and the number of apoptotic cells was then assessed using TUNEL staining and the effect of three independent variables of "groups", "concentration" and "exposure duration" was analyzed by using three-way ANOVA.

The results of three-way ANOVA indicated a significant interaction among variables on apoptotic index. Accordingly, the effect of "group" was significant $(\mathrm{F}(2,154)=25.79, \mathrm{p}<0.001)$, the effect of "concentration" was significant $(\mathrm{F}(1,154)=3.53, \mathrm{p}<0.05)$, and the effect of "exposure duration" was also significant $(\mathrm{F}(1,154)=$ $31.32, \mathrm{p}<0.001)$. Interaction of "group" $\times$ "concentration" and interaction of "concentration" $\times$ "exposure duration" were not significant, however interaction of "group" × "exposure duration" was significant $(F(2,154)=6.88, p=0.001)$. Interaction of "group" $\times$ "concentration" $\times$ "exposure duration" was not significant. 
For the comparison of apoptotic index within the experimental groups at each time point ( 24 or $48 \mathrm{~h}$ ), baseline ANOVA was also performed as followed:

\section{Opioid-induced apoptosis following 24 h exposure period}

In $24 \mathrm{~h}$ exposure subgroup, baseline ANOVA showed a significant difference in the number of TUNEL positive cells and the apoptotic index between the control group (cells exposed to agonist free medium) and agonist-exposed groups $(\mathrm{p}<0.0001)$ (Fig. 2). According to our results, the apoptotic index significantly increased from $13.86 \pm 1.38 \%$ in the control group to $28.92 \pm 3.3$ $\%$ and $38.78 \pm 2.22 \%$, in cells exposed to 1 and $100 \mu \mathrm{M} \mathrm{DAMGO}$, respectively $(p<0.001)$. In respect to DPDPE-exposed groups, no significant changes in apoptotic index were observed in comparison to the control group. However, in cells exposed to higher concentration of DYN 1-9 $(100 \mu \mathrm{M})$, apoptotic index significantly increased in comparison to the control as shown in Figure $2(p<0.01)$.

\section{Opioid-induced apoptosis following $48 \mathrm{~h}$ exposure period}

Similar to the results of $24 \mathrm{~h}$ exposure period, in $48 \mathrm{~h}$ exposure subgroup, a significant difference was found in the number of TUNEL positive cells and apoptotic index between the control and agonist-exposed groups ( $<<0.005$ ) (Fig. 3). Apoptotic index significantly increased from $22.06 \pm 3.15 \%$ in the control group to $32.08 \pm 3.1 \%$ in cells exposed to $1 \mu \mathrm{M}$ DAMGO, and $35.25 \pm$ $1.52 \%$ in cells exposed to $100 \mu \mathrm{M}$ DAMGO $(\mathrm{p}<0.01)$. No significant changes in the apoptotic index were observed again in DPDPE-exposed groups. In cells exposed to higher concentration of DYN 1-9, apoptotic index significantly increased in comparison to the control as shown in Figure $3(\mathrm{p}<0.05)$.

\section{HOURS EXPOSURE PERIOD}

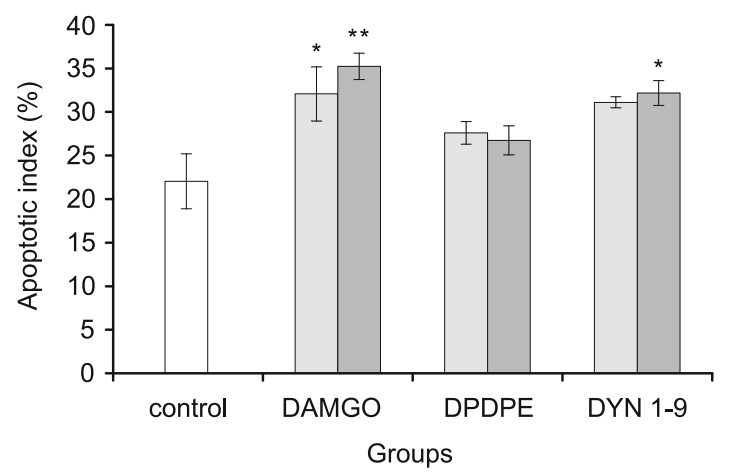

$\square 1 \mu \mathrm{M} \quad \square 100 \mu \mathrm{M}$

Fig. 3. The effect of opioid receptors selective agonists on TM4 cell apoptosis following $48 \mathrm{~h}$ exposure period. Comparison of the effects of two concentrations of MOR selective agonist (DAMGO), DOR selective agonist (DPDPE), and KOR selective agonist (DYN1-9) on apoptotic index of TM4 cells following 48 hours exposure period. * represents p $<0.05$ and ** represents $\mathbf{p}<0.01$ compared to the control group (baseline, one-way ANOVA). In order to show the most relevant results (difference between opioid groups and control), not all significant changes are shown. All results are presented as the mean \pm SEM.
Tab. 1. Comparison of the apoptotic index between 24 and 48 hours exposure periods.

\begin{tabular}{lccc}
\hline Opioid Agonist & $\begin{array}{c}\text { Apoptotic } \\
\text { Index } \%(24 \mathrm{~h})\end{array}$ & $\begin{array}{c}\text { Apoptotic } \\
\text { Index } \%(48 \mathrm{~h})\end{array}$ & $\mathrm{p}$ \\
\hline DAMGO $(1 \mu \mathrm{M})$ & $28.92 \pm 3.3$ & $32.08 \pm 3.1$ & $>0.05$ \\
DAMGO $(100 \mu \mathrm{M})$ & $38.78 \pm 2.22$ & $35.25 \pm 1.52$ & $>0.05$ \\
DPDPE $(1 \mu \mathrm{M})$ & $15.45 \pm 1.43$ & $27.62 \pm 1.3$ & $0.001^{* *}$ \\
DPDPE $(100 \mu \mathrm{M})$ & $13.61 \pm 1.9$ & $26.75 \pm 1.66$ & $0.001^{* *}$ \\
DYN 1-9 $(1 \mu \mathrm{M})$ & $20.43 \pm 2.36$ & $31.12 \pm 0.63$ & $0.002^{* *}$ \\
DYN 1-9 $(100 \mu \mathrm{M})$ & $25.4 \pm 1.73$ & $32.2 \pm 1.42$ & $0.003 * *$ \\
CONTROL & $13.86 \pm 1.38$ & $22.06 \pm 3.15$ & $0.01 *$ \\
\hline
\end{tabular}

Comparison between the effects of 24 and 48 hours exposure periods of two concentrations of MOR selective agonist (DAMGO), DOR selective agonist (DPDPE), and KOR selective agonist (DYN1-9) on the apoptotic index of TM4 cells (unpaired t-test). All results are presented as the mean \pm SEM.

A comparison between the effects of 24 and 48 hours exposure periods of two concentrations of DAMGO, DPDPE and DYN1-9 on apoptotic index of TM4 cells has been summarized in Table 1.

\section{Discussion}

In the present study, cell viability and apoptosis were investigated in TM4 Sertoli cells, exposed to mu, delta and kappa opioid receptors' selective agonists to clarify whether opioids acting on Sertoli cells may contribute to testicular homeostasis and/or reproductive dysfunction. The main findings were that the cell viability decreased and apoptosis increased in cells exposed to MOR selective agonist, DAMGO, in a concentration-dependent manner. There were no significant changes observed in the viability and apoptosis of cells exposed to DOR selective agonist, DPDPE. In cells exposed to KOR agonist, DYN 1-9, the viability did not significantly change, however apoptosis increased significantly in the cells exposed to higher concentration of DYN 1-9.

Endogenous opioids are present in the male reproductive system and are involved in the local control of testicular function. However, a growing body of evidence in humans and experimental animals indicates that long-term opioid abuse or opioid therapy leads to reduced sex hormone and sperm production, hypogonadism and male infertility. Endocrinopathy effects of opioids begin as soon as an opioid is taken and the prevalence of opioid-induced hypogonadism in patients taking chronic opioid therapy could be as high as $90 \%(7,30-31)$.

It is indicated that the opioid system can produce a certain degree of testicular dysfunction directly and/or indirectly by disrupting the HPG axis, sperm production, motility and modification and adversely affects endocrine function of testis and spermatogenesis. In spite of intensive studies on opioids-induced injury in testis, little is known about the effects of opioids on isolated Sertoli cells. Moreover, the question is still unanswered as to whether or not the opioid effects on testis Sertoli cells are due to a direct action of the opioids or may be due to altered hormone levels, which are necessary for the support of spermatogenesis and function of testis somatic cells.

Apoptosis is indicated as an important mechanism, by which opioids may be involved in testicular homeostasis or enhance toxi- 
city of testicular germ cells and somatic cells. Although there are many extensive studies about opioids and apoptosis, the potential effect of opioids to induce cell death by apoptosis is a controversial issue. Chronic exposure to mu opioid receptor agonists was reported to induce pro-apoptotic effects on various types of human and animal normal and cancer cell lines. Accordingly, morphine enhances apoptosis in brain tissue of laboratory animals $(21,32)$ and human endothelial (19) and immune cells (23), through upregulation of various proapoptotic proteins, nitric oxide and reactive oxygen species pathways. Induction of apoptosis by morphine in human lung and breast carcinoma and human tumor cell lines has also been reported $(22,33-34)$.

Although in the majority of previous studies the pro-apoptotic effects of morphine and other mu opioid receptor's agonists have been reported, controversial results of anti-apoptotic effects of mu opioid receptor have also been obtained in both normal cells (with controlled proliferation activity) including intestinal epithelium cells and cortical neurons (35-36) and tumor cells (with poor differentiation and previously enhanced proliferation activity) (37-39).

In spite of the above-mentioned controversies about the apoptotic effects of opioids, in the present study, the evaluation of cell viability via MTT assay confirmed that mu opioid receptor's selective agonist, DAMGO, decreased Sertoli cell survival and exhibited an anti-proliferation effect, in a concentration-dependent manner. Cell viability decreased as DAMGO concentration increased and eventually reached to $72 \%$ of the control level at concentration of $100 \mu \mathrm{M}$. Consistent with MTT data, a concentration dependent increase in TUNEL positive cells was also observed in cells exposed to DAMGO. These findings are in agreement with the majority of studies mentioned above, which showed that mu opioid receptor activation exerted apoptotic effects on different normal and tumor cells and tissues. Controversial pro and anti-apoptotic effects of mu receptor opioids can be justified by differences in mu opioid receptor subtypes and their distribution and expression patterns in different tissues, as well as the opioids concentration level and their affinity.

In respect to DOR, anti-apoptotic effects of this subtype have been shown in the majority of previous studies reporting an inhibition of apoptosis in liver cancer cells (40-41) and ischemia/ reperfusion-induced apoptosis of cardiocyte (42) and small intestine cell (35), through activation of DOR. However, in the present study, our data did not show any significant changes in the cell viability or apoptosis of healthy and normal Sertoli cells exposed to different concentrations of DOR selective agonist, DPDPE at none of the experimental time courses. However, it should be noted, that previous studies have been mainly focused on the effect of DOR activation on apoptosis-defective cells including tumor or ischemic cells, in which their proliferation capacity had been previously defected by tumor/ischemia-induced impairment of cell cycle regulation and proliferation related signaling processes. In the present study, normal Sertoli cells have been studied, in which their signals of apoptotic pathways have remained intact and not enhanced or inhibited. According to our results, DOR receptor activity in healthy normal Sertoli cells does not induce a significant effect on physiological apoptosis in normal conditions.
In respect to KOR, although pro-apoptotic effects of kappa opioid receptor's selective agonists have been reported in CNE2 human epithelial tumor cell line (43) and mouse neuroblastoma apoptotic cells (44), controversial results of anti-apoptotic effects of KOR have also been obtained in brain (45) and myocardial (46) ischemic cells. In the present study, our data did not show any significant changes in the cell viability of normal Sertoli cells exposed to different concentrations of KOR selective agonist, DYN 1-9. However, a significant increase in TUNEL positive cells was observed in cells exposed to $100 \mu \mathrm{M}$ DYN 1-9.

Some of the previous studies revealed a time-dependent effect of opioids on proliferation and apoptosis (47-51). According to our results, the apoptotic index was found to be increased in 48 hours exposure period in comparison to 24 hours in all of the treatment groups (except DAMGO $100 \mu \mathrm{M}$, table 1). This finding is consistent with that of Zagon and McLaughlin (2003), who showed that exposure of human cancer cell lines to DAMGO at 1 $\mu \mathrm{M}$ significantly increased the number of TUNEL positive cells from control levels, at all times points studied (51). However, because DAMGO has been used only at concentration of $1 \mu \mathrm{M}$ in the study mentioned above, the effects of higher agonist concentrations in longer exposure times could not be obtained and compared to our findings. According to our results, a reduced apoptotic index in cells exposed to DAMGO $100 \mu \mathrm{M}$ following 48 hours exposure period could be due to mu opioid receptor desensitization, when exposed to high agonist concentration during longer exposure duration. However, we are not able to conclude, based on our findings, time-dependent phenomenon of opioids effects on Sertoli cell apoptosis and proliferation, when comparing only two exposure times. On the other hand, a significant difference between 24 and 48 hours exposure to opioid-free medium in both of the control groups (Tab. 1) indicated a duration-dependent spontaneously-induced apoptosis, which makes it difficult to evaluate the direct impact of opioid per se. Moreover, duration dependent impairment of testicular function in opioid abusers or in experimental animals might be partially due to an impaired HPG axis, which is absent in our cell culture in vitro study. A more proper time-course study of opioid anti-proliferation and apoptotic effects is recommended.

Although previous results indicated a different action of opioids against proliferation and apoptosis of normal and tumor cells, these effects have mostly been shown to be mediated through opioid receptors, by activating different receptor subtypes and different signal pathways $(36,43,52)$. Pertinent to these point endogenous opioid peptides may, at low concentrations, promote cell survival perhaps through delta opioid receptors, whereas they may kill cells at high concentrations via the activation of mu opioid receptors. Due to the differences in methodology, the outcome measures and cell types make a direct comparison of our work with majority of other studies difficult, however, our findings suggest that MOR and KOR activity increase cell death in healthy normal Sertoli cells whereas DOR activity does not induce a significant effect on physiological apoptosis of Sertoli cells in normal conditions. In spite of mu and delta receptor mediated Sertoli cell apoptosis, a significant enhancement of cell death only occurred at higher 
concentrations of the agonists, which can influence the fine specificity and sensitivity of the receptor subtypes to these agonists. Despite this caveat, however, our data still provide a relevant information regarding the involvement of opioids in Sertoli cell apoptosis, which involves them in the regulation of testicular homeostasis and/or Sertoli cell-based reproductive dysfunction. A disturbance in balance between the factors controlling cell proliferation and those controlling apoptosis may lead to either insufficient or excessive apoptosis of Sertoli cells, which then can contribute to reproductive dysfunction and even infertility in patients taking opioid medications and in opiate abusers.

In conclusion, this study showed that the activation of opioid receptors in normal Sertoli cells resulted in an enhancement of apoptosis. Whilst multiple cellular signaling pathways involving the opioid-induced testicular toxicity could not be ruled out, it is hypothesized that mu and kappa, but not delta receptors mediated apoptosis in Sertoli cells might be involved, at least in part, in this phenomenon. Since opiates and their receptors are important for the regulation and normal function of the Sertoli cells, which in turn are involved in regular spermatogenesis, their abnormal levels caused by opioid abusers seem to be associated with reproductive disorders and even infertility. Whilst it is hypothesized that opioid might reduce fertility potential by increasing Sertoli cell apoptosis, future studies focusing on direct and indirect mechanisms of opioid action, especially apoptotic signaling pathways and hormonal regulatory networks are required to establish the precise nature of their interaction.

\section{References}

1. Wittert G, Hope P, Pyle D. Tissue distribution of opioid receptor gene expression in the rat. Biochem Bioph Res Co 1996; 218 (3): 877-881.

2. Monteillet-Agius G, Fein J, Phan T, Anton B, Lam H, Zaki P et al. Regulation and distribution of members of the opioid receptor family. Proc West Pharmacol Soc 1996; 39: 69-70.

3. Subiran N, Casis L, Irazusta J. Regulation of male fertility by the opioid system. Mol Med 2011; 17 (7-8): 846-853.

4. Fabbri A, Tsai-Morris CH, Luna S, Fraioli F, Dufau ML. Opiate receptors are present in the rat testis. Identification and localization in Sertoli cells. Endocrinology 1985 Dec; 117 (6): 2544-6.

5. Jenab S, Morris PL. Interleukin-6 regulation of kappa opioid receptor gene expression in primary sertoli cells. Endocrine 2000; 13 (1): 11-15.

6. Khademi H, Kamangar F, Brennan P, Malekzadeh R. Opioid Therapy and its Side Effects: A Review. Arch Iran Med 2016; 19 (12): 870-876.

7. Brennan MJ. The effect of opioid therapy on endocrine function. Am J Med 2013; 126 (3 Suppl 1): S12-18.

8. Daniell HW. Hypogonadism in men consuming sustained-action oral opioids. J Pain 2002; 3 (5): 377-384.

9. Pereska Z, Dejanova B, Bozinovska C, Petkovska L. Prooxidative/ antioxidative homeostasis in heroin addiction and detoxification. Bratisl Lek Listy 2007; 108 (9): 393-398.

10. Ragni G, De Lauretis L, Bestetti O, Sghedoni D, Gambaro V. Gonadal function in male heroin and methadone addicts. Int J Androl 1988; 11 (2): 93-100
11. Moradi M, Mahmoodi M, Raoofi A, Ghanbari A. Chorionic morphine, naltrexone and pentoxifylline effect on hypophyso-gonadal hormones of male rats. Bratisl Lek Listy 2015; 116 (4): 276-279.

12. Wang Y, Zhao X, Gao X, Gan Y, Liu Y, Hu J et al. Original endomorphin-1 analogues exhibit good analgesic effects with minimal implications for human sperm motility. Bioorg Med Chem Lett 2017; 27 (10): 2119-2123.

13. Shuey DL, Stump DG, Carliss RD, Gerson RJ. Effects of the opioid analgesic oxymorphone hydrochloride on reproductive function in male and female rats. Birth Defects Res B Dev Reprod Toxicol 2008; 83 (1): 12-18.

14. Vicente-Carrillo A, Alvarez-Rodriguez M, Rodriguez-Martinez H. The $\mathrm{mu}(\mathrm{mu})$ and delta (delta) opioid receptors modulate boar sperm motility. Mol Reprod Dev 2016; 83 (8): 724-734.

15. Fujisawa M, Kanzaki M, Okada H, Arakawa S, Kamidono S. Metenkephalin in seminal plasma of infertile men. Int J Urol 1996; 3 (4): 297-300.

16. Foresta C, Tramarin A, Scandellari C, Arslan P. Effects of a metenkephalin analogue on motility, $\mathrm{O} 2$ consumption, and ATP content of human spermatozoa. Arch Androl 1985; 14 (2-3): 247-252.

17. Albrizio M, Guaricci AC, Calamita G, Zarrilli A, Minoia P. Expression and immunolocalization of the mu-opioid receptor in human sperm cells. Fertil Steril 2006; 86 (6): 1776-1779.

18. Albrizio M, Lacalandra GM, Micera E, Guaricci AC, Nicassio M, Zarrilli A. Delta opioid receptor on equine sperm cells: subcellular localization and involvement in sperm motility analyzed by computer assisted sperm analyzer (CASA). Reprod Biol Endocrinol 2010 25; 8: 78.

19. Hsiao PN, Chang MC, Cheng WF, Chen CA, Lin HW, Hsieh CY et al. Morphine induces apoptosis of human endothelial cells through nitric oxide and reactive oxygen species pathways. Toxicology 2009; 256 (1-2): 83-91.

20. Singhal PC, Kapasi AA, Reddy K, Franki N, Gibbons N, Ding G. Morphine promotes apoptosis in Jurkat cells. J Leukoc Biol 1999; 66 (4): 650-658.

21. Boronat MA, Garcia-Fuster MJ, Garcia-Sevilla JA. Chronic morphine induces up-regulation of the pro-apoptotic Fas receptor and downregulation of the anti-apoptotic Bcl-2 oncoprotein in rat brain. Br J Pharmacol 2001; 134 (6): 1263-1270.

22. Hatsukari I, Hitosugi N, Matsumoto I, Nagasaka H, Sakagami H. Induction of early apoptosis marker by morphine in human lung and breast carcinoma cell lines. Anticancer Res 2003; 23 (3B): 2413-2417.

23. Kapasi AA, Coscia SA, Pandya MP, Singhal PC. Morphine modulates HIV-1 gp160-induced murine macrophage and human monocyte apoptosis by disparate ways. J Neuroimmunol 2004; 148 (1-2): 86-96.

24. Li J, Yan B, Liu Y. [Effect of nitric oxide synthase inhibitor on the testis cell apoptosis in morphine-dependent rats]. Zhonghua Nan Ke Xue 2004; 10 (11): 836-840.

25. Tang B, Zhang Y, Liang R, Yuan P, Du J, Wang $\mathbf{H}$ et al. Activation of the delta-opioid receptor inhibits serum deprivation-induced apoptosis of human liver cells via the activation of PKC and the mitochondrial pathway. Int J Mol Med 2011; 28 (6): 1077-1085.

26. Garcia-Fuster MJ, Ferrer-Alcon M, Martin M, Kieffer BL, Maldonado R, Garcia-Sevilla JA. Effects of constitutive deletion of opioid receptors on the basal densities of Fas and Fas-associated protein with death domain (FADD) in the mouse brain: a delta-opioid tone inhibits FADD. Eur Neuropsychopharmacol 2007; 17 (5): 366-374. 
27. Okubo S, Tanabe Y, Takeda K, Kitayama M, Kanemitsu S, Kukreja RC et al. Ischemic preconditioning and morphine attenuate myocardial apoptosis and infarction after ischemia-reperfusion in rabbits: role of delta-opioid receptor. Am J Physiol Heart Circ Physiol 2004; 287 (4): H1786-1791.

28. Pourhassanali N, Roshan-Milani S, Kheradmand F, Motazakker M, Bagheri M, Saboory E. Zinc attenuates ethanol-induced Sertoli cell toxicity and apoptosis through caspase-3 mediated pathways. Reprod Toxicol 2016; 61: 97-103.

29. Pourheydar B, Soleimani Asl S, Azimzadeh M, Rezaei Moghadam A, Marzban A, Mehdizadeh M. Neuroprotective Effects of Bone Marrow Mesenchymal Stem Cells on Bilateral Common Carotid Arteries Occlusion Model of Cerebral Ischemia in Rat. Behav Neurol 2016; 2016: 2964712.

30. Katz N, Mazer NA. The impact of opioids on the endocrine system. Clin J Pain 2009; 25 (2): 170-175.

31. Rajagopal A, Vassilopoulou-Sellin R, Palmer JL, Kaur G, Bruera E. Symptomatic hypogonadism in male survivors of cancer with chronic exposure to opioids. Cancer 2004; 100 (4): 851-858.

32. Bajic D, Commons KG, Soriano SG. Morphine-enhanced apoptosis in selective brain regions of neonatal rats. Int J Dev Neurosci 2013; 31 (4): $258-266$.

33. Maneckjee R, Minna JD. Opioids induce while nicotine suppresses apoptosis in human lung cancer cells. Cell Growth Differ 1994; 5 (10): 1033-1040.

34. Hatsukari I, Hitosugi N, Ohno R, Hashimoto K, Nakamura S, Satoh $\mathrm{K}$ et al. Induction of apoptosis by morphine in human tumor cell lines in vitro. Anticancer Res 2007; 27 (2): 857-864.

35. Shen JT, Li YS, Xia ZQ, Wen SH, Yao X, Yang WJ et al. Remifentanil preconditioning protects the small intestine against ischemia/reperfusion injury via intestinal delta- and mu-opioid receptors. Surgery 2016; 159 (2): 548-559.

36. Iglesias M, Segura MF, Comella JX, Olmos G. Mu-opioid receptor activation prevents apoptosis following serum withdrawal in differentiated SH-SY5Y cells and cortical neurons via phosphatidylinositol 3-kinase. Neuropharmacology 2003; 44 (4): 482-492.

37. Gupta K, Kshirsagar S, Chang L, Schwartz R, Law PY, Yee D et al. Morphine stimulates angiogenesis by activating proangiogenic and survival-promoting signaling and promotes breast tumor growth. Cancer Res 2002; 62 (15): 4491-4498.

38. Ishikawa M, Tanno K, Kamo A, Takayanagi Y, Sasaki K. Enhancement of tumor growth by morphine and its possible mechanism in mice. Biol Pharm Bull 1993; 16 (8): 762-766.

39. Simon RH, Arbo TE. Morphine increases metastatic tumor growth. Brain Res Bull 1986; 16 (3): 363-367.
40. Jia K, Sun D, Ling S, Tian Y, Yang X, Sui J et al. Activated deltaopioid receptors inhibit hydrogen peroxideinduced apoptosis in liver cancer cells through the PKC/ERK signaling pathway. Mol Med Rep 2014; 10 (2): 839-847.

41. Tang B, Li Y, Yuan S, Tomlinson S, He S. Upregulation of the delta opioid receptor in liver cancer promotes liver cancer progression both in vitro and in vivo. Int J Oncol 2013; 43 (4): 1281-1290.

42. Liu H, Zhang HY, McPherson BC, Baman T, Roth S, Shao Z et al. Role of opioid delta1 receptors, mitochondrial K (ATP) channels, and protein kinase C during cardiocyte apoptosis. J Mol Cell Cardiol 2001; 33 (11): 2007-2014.

43. Diao CT, Li L, Lau SY, Wong TM, Wong NS. kappa-Opioid receptor potentiates apoptosis via a phospholipase C pathway in the CNE2 human epithelial tumor cell line. Biochim Biophys Acta 2000; 1499 (1-2): $49-62$.

44. Dawson G, Dawson SA, Goswami R. Chronic exposure to kappaopioids enhances the susceptibility of immortalized neurons (F-11 kappa 7) to apoptosis-inducing drugs by a mechanism that may involve ceramide. J Neurochem 1997; 68 (6): 2363-2370.

45. Chen C, Xi C, Liang X, Ma J, Su D, Abel T et al. The Role of kappa Opioid Receptor in Brain Ischemia. Crit Care Med 2016; 44 (12): e1219-e1225.

46. Tong G, Sun Z, Wei X, Gu C, Kaye AD, Wang Y et al. U50,488H postconditioning reduces apoptosis after myocardial ischemia and reperfusion. Life Sci 2011; 88 (1-2): 31-38.

47. Dabbagh A, Rajaei S. The role of anesthetic drugs in liver apoptosis. Hepat Mon 2013; 13 (8): e13162.

48. Goswami R, Dawson SA, Dawson G. Cyclic AMP protects against staurosporine and wortmannin-induced apoptosis and opioid-enhanced apoptosis in both embryonic and immortalized (F-11kappa7) neurons. J Neurochem 1998; 70 (4): 1376-1382.

49. He L, Li H, Chen L, Miao J, Jiang Y, Zhang Y et al. Toll-like receptor 9 is required for opioid-induced microglia apoptosis. PLoS One 2011 29; 6 (4): e18190.

50. Dermitzaki E, Chatzaki E, Gravanis A, Margioris AN. Opioids transiently prevent activation of apoptotic mechanisms following short periods of serum withdrawal. J Neurochem 2000; 74 (3): 960-969.

51. Zagon IS, McLaughlin PJ. Opioids and the apoptotic pathway in human cancer cells. Neuropeptides 2003; 37 (2): 79-88.

52. Hayashi T, Tsao LI, Su TP. Antiapoptotic and cytotoxic properties of delta opioid peptide [D-Ala (2),D-Leu (5)]enkephalin in PC12 cells. Synapse 2002; 43 (1): 86-94.

Received January 1, 2019. Accepted February 15. 2019. 